\title{
Luis Landriscina narrador campesino y contador profesional. Desde los cuentos folklóricos al espectáculo de masas ${ }^{*}$
}

\section{Luis Landriscina, Rural Narrator and Professional Storyteller. From the Folk Tales to the Mass Culture}

\author{
Claudia MÉNDEZ \\ (Edlin School, Reston, Virginia, USA) \\ claudia.mendez641@gmail.com \\ ORCID ID: 0000-0001-9506-1858
}

\begin{abstract}
The objective of this article is to analyze the biography, the vital and cultural context, the verbal art, and three tales of lies (two of them take part in the repertoire of the «fishermen's lies»), told by the famous Argentine professional storyteller Luis Landriscina (born 1935). The artist's itinerary is studied from the peasant village, with its essentially oral culture, to the spaces and technologies of mass culture (theaters, cinema, television, records); the coined and exaggerated stereotypes of the narrator of small-town and rural extraction are singularly addressed and delves into the poetics of stories of lies in the first person.
\end{abstract}

Keywords: Short stories, fishermen's tall tales, oral tradition, Argentina, stereotypes, mass culture, profesional storytellers
RESUMEN: El objetivo de este artículo es analizar la biografía, el contexto vital y cultural, el arte verbal y tres cuentos de mentiras (el primero es un cuento de exageraciones, y los otros dos pertenecen al repertorio de las «mentiras de pescadores»), contados por el célebre narrador profesional argentino Luis Landriscina (nacido en 1935). Se estudia el itinerario del artista desde la aldea campesina, con su cultura esencialmente oral, hasta los espacios y tecnologías de la cultura de masas (teatros, cine, televisión, discos, internet); se atiende singularmente a los estereotipos acuñados y exagerados del narrador de extracción pueblerina; y se profundiza en la poética de los cuentos de mentiras en primera persona, en particular de las «mentiras de pescadores».

Palabras-clave: Cuento, cuento de mentiras de pescadores, oralidad, Argentina, estereotipos, cultura de masas, narración oral profesional

En homenaje a Luis Landriscina, maestro de la literatura y de la vida Y a la memoria de mi nunca olvidada maestra, María Cruz García de Enterría

* Agradezco su ayuda en la elaboración de este trabajo a mi maestro, José Manuel Pedrosa. También agradezco la atenta revisión de estas páginas a José Luis Garrosa. He revivido con emoción, mientras hacía este trabajo, todo lo aprendido en el curso de doctorado que tuve el privilegio de seguir en el año 1998 en la Universidad de Alcalá: un evento que cambió mi percepción de la literatura y, en cierto modo, de la vida. Fue impartido, en colaboración, por la añorada profesora García de Enterría y por el profesor Pedrosa. 
LA VIDA Y EL ARTE VERBAL DE LUIS LANDRISCINA (N. 1935)

La tradición oral argentina sigue siendo rica en voces, registros, recursos. La globalización ha afectado negativamente, como en todas partes, sus modos de transmisión y pervivencia, y ha hecho que en las últimas décadas menguara de manera importante su caudal y su variedad; no obstante, la riqueza de la tradición oral del país sigue siendo relevante. Eso si se exceptúa lo que ha sucedido y lo que sigue sucediendo en las comunidades originarias amerindias que se expresan en sus lenguas propias: tales pueblos llevan siglos sufriendo presiones y violencias crueles; ello se ha traducido en una enajenación dramática de su patrimonio lingüístico, literario oral, ritual y cultural, que se encuentra hoy en una situación muy precaria, más amenazada aún que la tradición oral cuya lengua vehicular es la española.

En cualquier caso, en mi país se sigue valorando como una virtud social la capacidad y la gracia en el uso de la palabra oral y del gesto y el aparato pragmático acompañantes. El buen narrador sigue siendo un personaje carismático y reconocido, tanto en los ámbitos rurales como en los urbanos, en la vida de la familia o entre el grupo de allegados, e incluso en los entornos profesionales. No en vano nos hemos ganado los argentinos, sobre todo los porteños, la fama de hablar mucho, quizás demasiado. Hay quien argumenta que es porque estamos practicando para hablar mejor.

Tal es el prestigio que tiene entre nosotros la palabra hablada y el aura de reconocimiento o de carisma con que tendemos a rodear a las personas que muestran dotes excelentes para narrar, a los argentinos se nos podría aplicar aquello que escribió Cristóbal de Villalón en torno a 1550, sobre el buen hablar y el buen narrar como méritos del buen cortesano (ahora diríamos del buen ciudadano):

El dia de oy es entre los hombres vn vso tan comun entre quales quiera condiçiones de varones en pasatiempos de combites o çenas no pasan su tiempo en mas para su conuersaçion y plazer. Preçianse todos de se motejar entre si: y entre su hablar vienen a dezir motes y graçias sabrosas y apazibles y a dezir cuentos, fabulas y façeçias con las quales se quieren recrear; y prinçipal mente quando el combite se ha çelebrado en vn deleytoso huerto o jardin: el qual es lugar mas aparejado para este genero de recreaçion como nos es agora a nosotros este (Villalón, 1967: 219).

En la tradición y el imaginario argentinos, el campesino o el gaucho (entiéndase esa voz en un sentido amplio, como el sujeto que sigue las tradiciones de su lugar) que destacaban o que destacan son los que tienen buenas costumbres, grandes habilidades en su oficio y manejo eficaz de la palabra y del ars narrandi; idealmente, ese gaucho ideal es el habitante o trabajador (ganadero, agricultor, peón) del campo de cualquier región argentina que, al terminar las faenas del día, era o es capaz de sostener conversación y de contar (y escuchar) relatos durante horas, entre sus iguales; mejor aún si además era o es poeta improvisador (payador) de décimas, que es otra de las habilidades (que hoy escasean) tenidas por representativas del campesino excelente. Las características que señalaremos en Luis Landriscina, representante emblemático del prototipo de buen narrador argentino y de pueblo, tienen mucho que ver con ese mundo social y cultural, con esa alta estimación que en Argentina se concede a quienes manejan con especial habilidad la palabra y a quienes tienen relación directa con la tierra, con el campo.

Ha habido en nuestro país un gran número de memoriosos narradores que comunicaron sus tesoros orales a nuestros grandes folcloristas, entre los que se cuentan nombres como los de Berta Elena Vidal de Battini, Augusto Raúl Cortázar, Martha Blache 
o, en nuestros días, Ana María Dupey, María Inés Palleiro o Pablo Rosalía Canatta. No estará de más apuntar que los nueve volúmenes de los Cuentos y leyendas populares de la Argentina de Vidal de Battini están considerados como la obra mayor, insuperada hasta hoy, de la recolección y la edición de la narrativa tradicional en cualquier país de la órbita hispánica. No incluyo en esta nómina a etnógrafos tan ilustres como Juan Alonso Carrizo, porque su especialidad fue, como es bien sabido, el folclore en verso cantado, y no la narrativa tradicional.

Escasamente reconocido y estudiado por el gremio académico es el repertorio de ciertos narradores profesionales que se han ganado y se siguen ganando la vida, en Argentina (y en otros países) contando en público, sobre escenarios teatrales o musicales, a veces en festivales, de una manera más o menos profesional. Sus repertorios están formados por relatos orales (casos, narraciones personales o memoratas, cuentos, leyendas) que hunden sus raíces en la tradición oral campesina, por un lado; pero que además son las muestras de, por otro lado, un arte personal, en cierto modo actoral, teatral, más o menos promocionado y remunerado, que les han abierto caminos en los espacios de la cultura de masas.

Estos narradores, que reciben en algunos lugares del mundo hispánico el nombre de humoristas, y que lindan también con los perfiles de los cuenteros o cuentacuentos, son personas que, con el instrumento de su voz, de sus gestos y de sus estilos personalísimos de expresarse, suben a escenarios, se presentan en eventos masivos, producen discos, tienen presencia en espacios mediáticos (radio, televisión, internet), adquieren fama y reconocimiento, ganan un sinnúmero de seguidores. Son continuadores, en cierta medida, de las habilidades de los juglares medievales, o de los comediantes y cantores callejeros de siempre, que iban de un lado para otro desplegando sus artes para ganarse la vida; la diferencia es que las tecnologías actuales, las de la cultura de masas, multiplican los alcances de esas artes; y de manera inevitable las transforman, las sitúan en otras órbitas de emisión, transmisión, recepción.

Una categoría singular dentro de este grupo de artistas de la voz y de estos repertorios es, ya lo he advertido, la de aquellos que se manifiestan como portavoces y encarnaciones de la cultura del pueblo, de la voz rural, del pueblerino, del gaucho a un tiempo ingenuo e ingenioso. Hay por supuesto narradores y humoristas que se acogen a otros perfiles y estereotipos más o menos reconocidos o acuñados. Pero el del rústico dicharachero que despierta risas al tiempo que ternura está muy asentado y goza de una sólida tradición.

Me voy a centrar en este estudio en una figura destacadísima dentro de esta categoría: en Luigi Landriscina (conocido por su nombre artístico: Luis Landriscina que es el que se usará de ahora en más) nació en 1935 cerca de Colonia Baranda, en el sudeste de la provincia del Chaco, en el seno de una familia procedente de Italia. Luis fue el séptimo de ocho hijos; su madre falleció al dar a luz a su octavo hermano. Fue criado por sus padrinos Margarita Martínez y Santiago Rodríguez, emigrantes españoles, de la provincia de León. Landriscina vivió inmerso en el mundo campesino durante su infancia y adolescencia. Pero se considera a sí mismo como un «casi gringo», porque nació de una familia de inmigrantes italianos y fue criado por una familia de inmigrantes españoles.

$\mathrm{Su}$ amor por su Chaco natal se asentó sobre esa experiencia temprana de unas raíces autóctonas muy profundas, pero también de los otros lenguajes e identidades que le venían de familia. Eligió ser un valedor de esas tradiciones sumadas, híbridas, y convertirse en vocero de las diferencias y variedades de las comunidades argentinas. Su voz camaleónica, capaz de asumir tonos y acentos argentinos diferentes, pero siempre 
enraizados en el mundo campesino o tradicional, tiene mucho que ver con ese mestizaje que le viene de nacimiento o de crianza. Landriscina es capaz de contar sus relatos fingiendo acentos y asumiendo identidades de unas cuantas regiones del país. Y no solo eso: tiene también la habilidad de meterse en la piel, en el idioma y en la idiosincrasia de los «gallegos» (generalización que se suele usar en Argentina para mencionar a todos los españoles), de los italianos, o de los «turcos» (denominación con la que hace referencia a las personas con raíces sirias, libanesas, o otros países del Oriente Medio).

Landriscina se casó en 1963 con Guadalupe Manceló y al año siguiente, en 1964, ganó el premio Revelación como cuentista y recitador en Cosquín. El festival de Cosquín, en la provincia argentina de Córdoba. Este festival es el más importante en su género desde hace seis décadas, ha consagrado a muchos artistas populares de la voz; durante las nueve noches del mes de enero que suele durar compiten en él solistas y conjuntos de música y baile tradicional; alrededor del festival oficial proliferan además las peñas informales y espectáculos espontáneos callejeros de música y baile.

Después de recibir el espaldarazo de aquel premio, durante los siguientes años hizo Landriscina presentaciones en locales provinciales como «La tribuna de los Farías Gómez» y «La Peña de Fanny». El concepto de peña en Argentina es bastante específico, se trata de un lugar donde se sirven bebidas y comida, pero fundamentalmente donde hay música folclórica en vivo. La gente va a bailar o a escuchar música o narradores, pero a veces son los mismos espectadores los que presentan. Es un local comercial, generalmente pequeño e informal, donde la música es el principal componente. Estos lugares de encuentro permitieron una profesionalización precaria de artistas locales y populares. Proliferaron fuera de los circuitos de las ciudades y la gente presentaba y consumía alternativamente. Se conocen solo algunos que tuvieron la suerte de permanecer más tiempo. También fue Landriscina voz habitual en radios locales, cuando la radio era el más popular de los medios entre la población rural y de los pueblos.

En 1967 se mudó con su familia a Buenos Aires, y al poco tiempo se convirtió en personaje reconocido gracias a sus apariciones frecuentes en la radio y la televisión nacional. Contó en varias entrevistas muy posteriores que recién en 1969 fue cuando empezó a «comer seguido» de su trabajo; antes no siempre había tenido aquella suerte.

Por aquel entonces firmó su primer contrato discográfico; aparecía además en «Sábados continuados» entre otros programas muy conocidos en la televisión argentina, y en el programa de radio «Mano a mano con el país» tenía colaboraciones permanentes. En 1970 se presentó en unos ciento treinta festivales a lo largo y ancho del país. En 1977 tuvo su propio espectáculo en el Teatro Coliseo: «El mundo de Landriscina». A medida que ganaba fama concurría a menos festivales en vivo y participaba en más programas para la radio y la televisión.

En la base de datos cinematográficos IMBD ${ }^{1}$, Luis Landriscina aparece como actor en algunas películas y series como: Joven, viuda y estanciera (1970 película), La gran ruta (1971 película), Historias de Nosédónde, 3 episodios (1971 serie para televisión),

${ }^{1}$ La base de datos de IMBd es uno de los mayores repositorios de películas y series televisivas continuamente actualizada internacionalmente. Pertenece actualmente a Amazon, pero sigue ofreciendo gratuitamente material audiovisual e información cotejada de las mismas producciones que detalla, hay un servicio de subscripción para los que quieren hacer comentarios o hacer listas de material. El dato de que Landriscina aparezca en varias series y películas es otra prueba de que profesionalmente hizo muchas cosas interesantes, aquí se dedica atención a su faceta de narrador, lo demás es parte de su biografía, pero siempre se puede ampliar con este material visual. 
¿De quién son las mujeres? (1972 película), El casamiento del Laucha (1977 película), Millonarios a la fuerza (1979 película), La estación de Landriscina, 5 episodios (1992 serie para televisión), Sapucay, mi pueblo (1997), y Almacén de campo, 3 episodios (2002 serie para televisión). Hay mucho más, pero estas citadas están disponibles para el público interesado.

En los últimos años sus nietos han puesto algunos de sus registros visuales y de audio en las redes sociales: YouTube, Facebook, Instagram. Su canal se llama: Luis Landriscina Oficial. Testimoniando el país con sonrisas. De ese modo, muy anciano ya, continúa llegando a un público fiel y de siempre, y al mismo tiempo que llega a un público nuevo, más joven. Están disponibles en internet, además, muchas entrevistas y la mayoría de las películas en las que actuó y series en las que actúo. Esto le permite extenderse más allá de su influencia sincrónica, y continuar contando diacrónicamente cuentos tradicionales y otros propios, creados o mejorados en sus versiones.

Hay que resaltar la importancia que en el recorrido vital y profesional de Landriscina y en la memoria común de la Argentina tuvieron sus discos y cintas de casete, que publicó por lo general en Philips y Polygram. En esos registros podemos apreciar las características de sus actuaciones en vivo, porque se le escucha interactuar con el público y recibir aplausos espontáneos. Aunque hay que advertir que muchos de esos discos no fueron resultados de tomas en vivo, sino de simulación de las condiciones del teatro en el estudio de grabación. Entre sus títulos más conocidos encontramos: Mateando con Landriscina, Landriscina por Landriscina, El humor de mi país, Contata criolla (1973), Luis Landriscina actúa para usted (1974), Del Chaco a América del Norte (1975), Mano a mano con el país (1981), Lo que sobra no se tira (1987), Landriscina: es mundial (1990), Contador público nacional (1992), Venga y le cuento (1995), Campeón del humor (1996) y El chiste no es cuento (2003). Hay mucho más, y siguen apareciendo nuevas recopilaciones.

Además de su labor como contador y recitador, actor de cine y radio, Landriscina escribió libros de poesía y de narrativa. En poesía se destacan: Con gusto a Chaco (1967) y Mis versos (1972), el primero era un cuadernillo rústico y el segundo fue una edición del autor. Lo importante es que allí aparecen los personajes a los que va a dedicar una gran parte de su esfuerzo artístico. Ahí están los personajes y las historias del Chaco, los casos «sucedidos» a él o a sus conocidos, pero tienen tonos realistas y dramáticos. De aquella época juvenil es su poema «Casi gringo», que presentó en Cosquín en su primera aparición y que ha seguido recitando a lo largo de su carrera. Landriscina asegura que le duele y le conmueve recitarlo, porque contiene una evocación de la muerte de su madre, es una autobiografía en verso. Es notable que muchos de sus poemas estén impregnados de realismo social, incluso de drama o de tragedia en las historias de vida que cuenta, porque el resto de la producción de Landriscina se ha orientado decididamente hacia lo cómico.

Hay otro grupo de libros que llevan la firma de Landriscina y que son transcripciones más o menos fieles de sus cuentos escénicos. Destacan Aquí me pongo a contar: los mejores cuentos de Luis Landriscina (1996), De todo como en galpón: cuentos, versos, dichos, anécdotas y algo más (1994), Cuentos para que se rían los chicos (1996), Querido Luis: lo mejor de Luis Landriscina (1999), Don Luis Landriscina y su querida Argentina (2001). Ha escrito además libros en colaboración, como El milagro de la vida (2012), firmado con René Favaloro y Mamerto Menapace, y Los valores con humor (1998), en colaboración con el mismo Menapace. E incluso algún artículo sobre los «Alcances terapéuticos del humor» (Landriscina, 1995). Toda su producción escrita está impregnada 
de inteligencia, de saber y de ética: es decir, de las mismas virtudes que afloran cuando presenta los mismos relatos de viva voz.

Es muy sintomático que el personaje de ficción que durante varias décadas estuvo interpretando Landriscina, casi a diario, primero en Radio Rivadavia y más tarde en Radio Nacional, el que más fama en todo el país le dio, se llamase precisamente don Verídico; y que en él manifestase la encarnación de un gaucho locuaz, ocurrente, fantasioso, exagerado. Todos los que conocen el arte de Landriscina saben que los equívocos y los juegos con la verdad y con la mentira son el eje de su poética y de su filosofía. Un nombre como don Verídico es, por eso, toda una (irónica) declaración de intenciones, una poderosa y paradójica tarjeta de presentación. Es necesario recordar que el personaje de Don Verídico fue interpretado por varios actores, pero el creador es un autor uruguayo: Julio Cesar Castro: Juceca. Landriscina es el más famoso de los interpretes del personaje.

El formato con que se representaba en la radio era bastante simple: un locutor conversaba con el personaje cómico: don Verídico y de cada sesión de charla surgían relatos y anécdotas graciosos o disparatados, diferentes en cada ocasión. El lenguaje formulario era rasgo muy distintivo de su discurso. «Hombre que supo ser, ahora que dice...»: tal era la fórmula con la que empezaba regularmente cada relato. Seguía un nombre inverosímil y aparatoso como: «Benemérito Sumizo» «Fofeto Fulero» o «Gutural Mollejo casado con Masculina Solera»; y tirando de hilos de esa especie comenzaban unos relatos disparatados en tono popular. Así, Landriscina dándole voz a Don Verídico podía afirmar, después de algún introito de esa especie, que la tal mujer se reía tanto que la contrataba para las fiestas, pero la prohibían en los velorios.

En el ciclo de Don Verídico había ciertos personajes fijos en la mayoría de los relatos, que solían estar ambientados en el boliche (en este contexto boliche significa un almacén de ramos generales donde se despachaban bebidas) «El Resorte». Popularísimos fueron «El Tape Olmedo» (invariablemente borracho), «La Dubija» (posiblemente la dueña del boliche), «El Barcino» (el gato), «Rosarito Verdoso» (uno de los contertulios), quien solía andar pelando higos y opinando acerca de todo lo divino y lo humano. A ese lugar mítico llegaban diferentes personajes a pedir consejos o a interactuar con los personajes fijos, todo estaba contado por el narrador poco fidedigno: Don Verídico.

Y, en el mejor estilo de Las mil y una noches, el gran cuentero solía dejar sus fábulas sin terminar en el día, y emplazar a su auditorio a conocer el desenlace en el siguiente programa.

\section{MÁS SOBRE EL ESTEREOTIPO DEL CAMPESINO LOCUAZ, EXAGERADO, INVENTIVO O MENTIROSO}

Cabe insistir en que lo que hizo Landriscina en Argentina no fue sino acomodarse a un patrón de arte verbal e histriónico internacional (y de antecedentes muy viejos y prestigiosos) que se basa en la representación del pueblerino medio ingenuo y medio ingenioso, con un estilo de hablar muy característico, más o menos risible, y dotado de una ideología y de una cosmovisión a un tiempo rudimentarios, tiernos, tolerantes, generosos. El Sancho Panza cervantino, incansable productor de relatos y de dichos vulgares, sería un antecesor muy ilustre; y antes de la famosa criatura de Cervantes habría que considerar también a los campesinos estereotipados (con sus lenguajes sobrecargados de dialectalismos y de vulgarismos) de Juan del Encina o de Lucas Fernández.

Sayagueses, gallegos, asturianos, vizcaínos, aragoneses, extremeños, andaluces de diversas áreas, gitanos, han sido, a lo largo de los siglos, encarnaciones en España 
de prototipos cómicos, cada uno con sus modos característicos (o estereotipados, o manipulados) de expresarse y de actuar. Pero también en la misma Argentina han gozado de popularidad personajes cortados por esos patrones. La literatura gauchesca es un repertorio en el que abundan las representaciones de esa especie. Una de sus manifestaciones maestras, el Fausto, Impresiones del gaucho Anastasio el Pollo en la representación de esta ópera (1866), de Estanislao del Campo, obra clave de la literatura argentina temprana, podría ser un ejemplo emblemático.

En otras regiones y países de Hispanoamérica han tenido enorme popularidad estos perfiles de narradores y de narraciones característica o exageradamente «rústicos»o «pueblerinos». Una de sus encarnaciones más célebres es, por supuesto, la del mexicano Mario Moreno, Cantinflas (1911-1993). Pero hay muchos otros, aunque no se hayan convertido en celebridades globales. En Honduras, por ejemplo, forman parte del imaginario nacional las llamadas perras o chistes de mentiras y exageraciones, y más en particular las llamadas perras de Teofilito, es decir, las perras de Teófilo Trejo, quien fuera un notabilísimo artista de la voz y del gesto que compartió muchos rasgos de poética y de filosofía vital con el argentino Luis Landriscina:

En Honduras ha gozado de gran popularidad el humorista Teófilo Trejo, Teofilito (1941-2016), que actuó en muchos escenarios, pero que se hizo particularmente famoso con la publicación de diversos libros:

En 1988, se presenta el primer libro de Teófilo Trejo, titulado Las perras de Teofilito, en el que recrea anécdotas, situaciones de la vida cotidiana, relatos, dichos, tópicos del imaginario campesino narrados con un toque de fantasía, humor y crítica social, y con un arte verbal desbordante. Las perras son una voz autóctona, que la Real Academia de la Lengua define como 'Hond. Chascarrillo', y constituye un género muy tradicional en mi país.

Podríamos definir las perras como relatos en primera persona, que simulan ser reflejos de experiencias vividas o de casos vistos o conocidos, pero que tienen un ingrediente fabuloso, cómico o disparatado muy importante.

El poeta dramaturgo Juan Ramón Sarabia ha manifestado que «las perras son productos literarios de primera mano, trompos que hay que echarse a la uña sin perder el impulso, relámpagos verbales que debemos captar tal como surgen de la cantera popular [...] Hay que ir entendiendo que los relatos que llamamos perras no son solo literatura sino un rasgo cultural centroamericano, y que entre nosotros constituye una forma de hondureñidad [...] Las perras hondureñas están llenas de autenticidad por ser nada menos que una muestra del ingenio popular; son vida diaria llevada al plano de la anécdota libre, robusta y desenfadada, en condiciones sociales que a menudo son todo lo contrario. Y las perras son una de las cosas más cercanas al hondureño común [...] Teófilo tiene la naturalidad del realismo mágico y la capacidad de soltarse al saco de la risa [...] Con la publicación de estos relatos se abre una inmensa veta en la literatura hondureña porque seguramente habrá muchas otras oportunidades para la inagotable fuente de las perras».

Otras obras del mismo autor son Cuéntame otra, Teofilito (1989), ¡Qué perrero es Teofilito! (2000), Seguís perreando, Teofilito (2007), Son puras perras, Teofilito (2008). Títulos que reflejan unos modos de narrar y un género literario, el de los cuentos de mentiras y casos exagerados (Martínez Reyes, 2016: 62-63).

Teófilo Trejo, Teofilito, era sobre todo un narrador-actor-histrión, y sus libros no fueron sino reflejos de algunos de los relatos que él solía contar en sus actuaciones. Algo parecido podría decirse de los libros e incluso de los discos de Landriscina, que son reflejos del arte que subía regularmente a los escenarios. En internet es posible encontrar 
algunas muestras, en video, del arte de Teofilito, lo que facilita la comparación con el arte de Landriscina.

Tampoco han faltado en España los narradores orales-actores que se dedicaron más o menos profesionalmente a explorar (en el teatro, la radio, el cine, la televisión, los discos) las variaciones lingüísticas, los dichos, el folclore, los estereotipos de los aldeanos (pintados por lo general como a veces listos y a veces tontos) de determinadas áreas campesinas del país. En el imaginario colectivo español siguen siendo muy recordados artistas de ese sesgo, como Paco Martínez Soria (1902-1982), Miguel Gila (1919-2001) o Fernando Esteso (1945), entre otros.

Aunque a primera vista estos campesinos locuaces, con sus hablas que a muchos pudieran parecer ridículas o estrafalarias, parece que se inclinan hacia el estereotipo del rústico necio o tonto, lo habitual es que acaben imponiendo sus destrezas verbales y sus puntos de vista, y dejando en evidencia o en ridículo a los representantes de la cultura letrada, urbana, de las instituciones o de las elites, con sus hablas más ilustradas, pero también más vacías y falsas. Las controversias entre personajes campesinos (de cultura esencialmente oral) y personajes urbanitas (de cultura esencialmente letrada) son muy bien conocidas en muchas culturas; la tradición común ha solido decantarse por lo general en favor de los primeros, a los que ha premiado con los laureles de la inteligencia y de la astucia, y en contra de los segundos, a los que suele humillar o castigar por su petulancia o su soberbia. Como excelentes administradores del logos, del lenguaje, e incluso como héroes lógicos o traductores: así han sido caracterizados en ocasiones ${ }^{2}$. Landriscina y otros narradores orales consagrados a encarnar los perfiles de los campesinos han mantenido ejemplarmente el testigo de esa vieja tradición, insuflando en sus criaturas agudeza, bondad y sentido de la justicia.

Este triunfo verbal del hombre de campo sobre el de ciudad sirve para la identificación de grandes grupos cuyos hijos y nietos saben más sobre los «manga» japoneses que sobre las costumbres y tradiciones de su entorno local. Estos artistas a los que se mencionan siguen siendo artísticas formas de resistencia cultural.

\section{DEL CUENTO TRADICIONAL DE MENTIRAS A LA CULTURA «DE MASAS»}

Sobre los cuentos llamados de mentiras (en inglés suelen ser llamados tall tales) existe ya una bibliografía relativamente abundante, aunque es evidente que se trata de una de las parcelas de la narrativa oral que más precisada está todavía de atención y estudio $^{3}$. Se refiere a los cuentos que están indexados con los números 1875-1999 (Tall Tales) en el catálogo de cuentos internacionales de Aarne-Thompson-Uther (2004). En el ámbito hispánico, especialistas como Lara Garrido (1982), Chevalier (1999) y José Manuel Pedrosa (2019) han producido ya estudios relevantes acerca de ellos. Aunque la compilación y el estudio maestros de los cuentos de mentiras en el mundo panhispánico es sin duda el gran libro del folclorista Ricardo Pieretti (2012) acerca de la tradición de los cuentos de mentiras (causos), según sigue viva (aunque en inevitable declive) en la

\footnotetext{
${ }^{2}$ Véase al respecto Pedrosa (2008, 2018 y 2021).

${ }^{3}$ Los cuentos de mentiras o tall tales han sido estudiados sobre todo en el mundo anglosajón. Véanse por ejemplo Schmitz (1977), Caron (1986), Wonham (1989), Bennett y Smith (2007) y Fee y Webb (2016). Hoy existe incluso un muy interesante portal de internet, producido por la folclorista y ensayista Schlosser, que contiene material fascinante para ampliar estos temas: https://americanfolklore.net/folklore/tall-tales/

Otro estudio clásico acerca de los cuentos de mentiras daneses es el de Henningsen (1965).
} 
agreste región del Pantanal brasileño. En el repertorio recogido por Pieretti, las mentiras asociadas a los trabajos de campo, la caza y la pesca, tienen una presencia relevante.

Según quienes han abordado su estudio, los cuentos de mentiras en general se caracterizan no solo por el empleo de la hipérbole y de la ironía como recursos estilísticos fundamentales. También por el uso de la primera persona homodiegética, es decir, por la presencia de una voz cantante que afirma que el suceso que narra le sucedió a ella misma; en alguna ocasión se asegura que le sucedió a algún sujeto o familiar próximo. Los rasgos de la primera persona homodiegética y del estilo hiperbólico, fuertemente patético, se asociaron de manera característica, también, a la novela picaresca española (y a otras obras europeas relacionadas con ese género, como Der abenteuerliche Simplicissimus Teutsch, 1668, de Hans Jakob Christoph von Grimmelshausen), que puede que sea un repertorio literario más cercano al cuento de mentiras que lo que hasta ahora ha sido considerado ${ }^{4}$.

Es evidente pero no suficiente la adscripción de muchos de los relatos que forman parte del repertorio de Landriscina al género de los cuentos de mentiras. Ese simple etiquetado no basta para definir el arte dinámico, experimental, híbrido, heterodoxo, del narrador argentino, ni de otros narradores de su especie. El cuento de mentiras es solo una de sus raíces. En el ars narrandi particular de Landriscina (y de otros narradores de su estirpe), en tanto que salido o salidos del recinto del campo e instalado o instalados, con los inevitables cambios y re-significaciones, en las ciudades, en los teatros, en los estudios de grabación, en las salas de cine, cabe detectar muchos otros vectores de influencia e impregnación. No me es posible identificarlos ni caracterizarlos todos en detalle, porque los años (entre la década de 1960 y los primeros años del siglo XXI) en que desarrolló Landriscina su actividad vieron una auténtica revolución en los usos sociales y culturales, que impactó de lleno en el repertorio literario en que indagamos. La vida de nuestro narrador arrancó de un mundo rural en que la oralidad local era el marco esencial de las relaciones entre las personas y voces; y hoy se sigue desarrollando en un mundo global, en que el marco lo provee cada vez más internet, que conecta virtualmente, pero sin contacto directo, a un número inconmensurable de sujetos.

De ahí que los cuentos de Landriscina (orales, escritos, radiados, televisados, en YouTube) se puedan considerar también, por un lado, como muestras de lo que García de Enterría (1983) llamaba «literaturas marginadas», que eran producidas en estilo del pueblo y para el consumo del pueblo; o de lo que Leonardo Romero Tobar ha denominado «literatura de consumo popular» (1999). Y no solo eso: son manifestaciones, además, de lo que también ha sido llamado «cultura folk», «folklore de masas», «folklore mediático», «folklore global», etc. ${ }^{5}$. Por lo demás, cabe poner en relación el arte de Landriscina y de los demás portavoces de su gremio con lo que ha sido llamado «narración oral» escénica y profesional (sus portavoces reciben muchas veces los nombres de «cuentacuentos»o de «cuenteros») que ha cobrado enorme auge, en las últimas décadas, en España, en América, en el mundo ${ }^{6}$.

\footnotetext{
${ }^{4}$ Véase, sobre la homodiégesis en la novela picaresca, el libro fundamental editado por MeyerMinnemann y Schlickers (2008)

${ }^{5}$ Sobre el tránsito de la cultura oral tradicional a la cultura de masas y a la cultura global, a través de los cauces mediadores del papel, la radio, la televisión, internet, existe una bibliografía gigantesca, que es imposible siquiera resumir aquí. Solo quiero destacar el libro clarividente de Dégh (1994). Y, en el ámbito hispánico, los trabajos de Díaz Viana (2003 y 2004).

${ }^{6}$ Véase al respecto Sanfilippo (2007).
} 
Dado que no es posible entrar aquí en detalles, sino solo dejar sintéticamente fijados algunos de sus marcos, paso ya a transcribir y a analizar de manera particular algunos de los relatos de Landriscina. El primero es un cuento de exageraciones, una forma de mentira, se llama «La maestra fiera ${ }^{7} »$ y los otros dos son específicamente de mentiras y están claramente englobados con los cuentos de mentiras de pescadores. Son «Pescao de patio»y «El viejo mentiroso».

\section{LA MAESTRA FIERA QUE FUE BURLADA POR EL PUER SENEX CAMPESINO}

El primer relato de Landriscina al que nos vamos a asomar, el de La maestra fiera, se corresponde con la primera etapa de Landriscina como contador. Apareció por primera vez en el disco El chiste no es cuento (Live in Buenos Aires) que publicó la casa Phonogram en 1974, aunque lo más probable es que formase parte del repertorio del narrador desde tiempo antes. Landriscina lo siguió contando durante años en la radio y en la televisión, y volvió a publicar otra versión discográfica en 2004. Una versión escrita fue publicada en Landriscina, 1999. Esa es la que reproduzco. Hay que avisar, por supuesto, de que cada versión que Landriscina contaba en público o grababa en disco o publicaba en libro tenía variantes, en ocasiones importantes, con respecto a las demás versiones:

\section{La maestra fiera.}

Me acuerdo de una maestra que tuve, allá por el tercer o cuarto grado, que era muy fiera.

Y la otra vez me preguntaba a uno de mi zona:

- ¿Y la sigue viendo?

— ¡Nooo ... hace mucho que no la veo! Además, no la quiero ver, porque yo me asustaba de chico nomás, no dormía de noche.

Para que se den una idea: la primera hora de clase la saludábamos mirando al piso para no asustarnos.

En la tercera hora ya volvíamos del segundo recreo y veníamos saboreando todavía el pedazo de pan crocante que nos habían entregado para ir al recreo y que nosotros, los que veníamos con ganas de comer de antes, lo hacíamos durar. No lo devorábamos como algunos suponían: comíamos la mitad, y la otra mitad iba al bolsillo para ir comiendo de a poco.

Y eso no le gustaba a la maestra, porque estábamos en la hora de clase pellizcando de adentro del bolsillo el pan ese que nos daba la cooperadora.

Y entonces ella decía:

- iA ver, queridos, las manos sobre el pupitre! ¡Saben que a mí no me gusta que coman en el aula, a mí no me gusta! Bueno, hoy en la tercera hora tenemos lenguaje, queridos. En lenguaje vamos a tratar el tiempo de los verbos. A ver... por ejemplo... a ver vos, Luisito.

Y me encaró a mí. Yo era un tipo estudioso. Me preocupaba mucho saber porque no me gustaba que me reten. Y yo sabía, pero me preguntó muy de golpe, y me atoró. Y como a cualquier chico que sabe y que le preguntan de golpe, yo también me paro y le digo:

-Sí, señorita.

—Por ejemplo, querido, a ver Luisito. «Yo fui al cine». ¿Qué tiempo de verbo es?

${ }^{7}$ Aquí fiera significa fundamentalmente: fea, este uso de la palabra es común en toda la Argentina. Este relato que se presenta en esta historia está en oposición a otro de los famosos poemas recitados de Landriscina: «La maestra de campo» donde describe la llegada de una maestra rural a su destino laboral y se la describe como bella y joven. La maestra del poema y la maestra del cuento se diferencian en muchos aspectos, también el tono de los textos. 
Y empecé a mirar pa arriba, pa abajo, pa los costales, y le dije:

- Yo fui al cine, este ... yo fui al cine...

— ¡Querido, la palabra te lo está diciendo! ¡«Yo fui al cine»! ¡ «Yo fui al cine», querido!

—Ah, eh... ¡Tiempo pasado!

—Mmmmm bien ... pero hay que estar más atento, Luisito, ¿eh? Hay que estar más atento. A ver vos, Miguelito...

Y se para Miguelito.

—Por ejemplo... ¿qué tiempo de verbo es «yo estoy comiendo»? Es lo que ustedes están haciendo recién, ¿no? «Yo estoy comiendo»: no me contestes una barbaridad, ¿eh?

-Yo estoy comiendo... eh... itiempo presente!

— ¡Muy bien, así se contesta! A ver vos, Fabián.

¡Aaaaah...! El Fabián era el vago del grado. Ese que lo ponen en el fondo del aula pa’ que no descomponga al resto. Con la gomera al cuello, los bolsillos del guardapolvo llenos de balines de barro para tirar con la honda... los dedos afuera de la alpargata desparramados como estornudo de ñato, despeinado que parece peinado con un cuete.

—iPárese bien!

Ensayaba una manera de pararse el Fabián.

—Bueno — dice la maestra—. Fabián, ya escuchó a sus compañeritos: Luisito ha dicho «yo fui al cine, tiempo pasado»; Miguelito ha dicho «yo estoy comiendo, tiempo presente». Por ejemplo, a ver ... ¿qué tiempo es «yo busco novio»?

- Tiempo perdido, señorita.

Es este un ejemplo preclaro del humor aparentemente blando y tierno, pero en realidad punzante y crítico de Landriscina. Para empezar: en pocos párrafos nos hace partícipes de un concentrado Bildungsroman, es decir, de un relato de iniciación infantil. La mayoría de los títulos del género del Bildungsroman contiene, como es sabido, escenas de niños en la escuela, o inmersos en procesos de formación o de instrucción.

Los paralelos de los que podríamos acordarnos son muchos: recuérdense los varios capítulos de La vida del Buscón en que los niños de Quevedo caen bajo la férula tiránica del Dómine Cabra o bregan en los ámbitos de otras instituciones educativas, incluso universitarias; o las peripecias entre la escuela y la calle de los héroes niños de Charles Dickens (que a veces introducía a sus ingenuas criaturas en escuelas de delincuentes, como hizo en Oliver Twist); o las muy populares novelas «de internados», como las de la serie Harry Potter, de J. K. Rowling, entre muchas otras.

Landriscina no solo nos sitúa, en este relato de la maestra fiera y de sus alumnos temerosos, en un típico Bildungsroman o relato de iniciación en un marco escolar, sino que logra además la proeza de presentárnoslo como un «caso» autobiográfico, que a él mismo le había acontecido cuando era niño. Ello choca con el hecho de que nosotros sabemos que estamos ante un tipo de ficción muy acuñado, de hechuras típicamente trimembres, con tres peripecias sucesivas que dan voz a tres sujetos, el último de los cuales se sale por la tangente y precipita un desenlace sorprendente e hilarante. Se trata de un esquema que conocemos de innumerables cuentos y relatos estructurados en tres partes, muchos de ellos disparatados. Pero aceptamos de buena gana que Landriscina nos lo comunique como caso real o autobiográfico: tan bien lo cuenta que no merece la pena al auditorio renunciar al disfrute de la escucha para entrar en escrúpulos de si aquello sería verdad o no.

Eso en el plano formal. En el plano del contenido, el relato de Landriscina no es menos magistral ni resulta menos memorable. Primero por su trasfondo de crítica social: el que, como él testifica, hubiera niños que vivían en los umbrales de la pobreza y que tenían 
hambre, y el que estuviesen sometidos al dominio de maestras «fieras», que causaban miedo en vez de respeto o admiración, son ya, de por sí, hechos que llaman a la reflexión y por supuesto indicios de crítica social y política, pues esos hechos lamentables reflejan en cierta medida (aunque Landriscina lo vistiera todo con ironía y hasta con ternura) un sistema pedagógico insuficiente y disfuncional.

Y en segundo lugar porque Landriscina se las arregla para señalar como vencedor del enfrentamiento dialéctico e ideológico al tercer niño, al ingenioso, ocurrente, inconformista, sobre la maestra de discurso dogmático y arrogante. El tercer alumno, el que logra burlar a la maestra con el arma exclusiva de la palabra (los dos alumnos anteriores habían ajustado sus discursos al de ella), se convierte así en una especie de improvisado héroe traductor, de excelente y rebelde dominador del logos, que logra imponerse en la pugna contra el discurso del poder, de la norma, de la institución, de la represión, del miedo.

Apurando más, el tercer niño se nos revela, con la sola, fulgurante, económica frase que cierra el relato de Landriscina, como un auténtico puer senex, como un niño sabio o experto, es decir, como la encarnación de un tipo heroico que cuenta con un currículum literario y cultural venerable: recuérdese que en esa categoría se podría incluir, por ejemplo, al niño Jesús que debatió, cuando tenía siete años, con los doctores del templo; o al ya mencionado Harry Potter ${ }^{8}$.

El relato de Landriscina no es, pues, en absoluto banal, de ninguna manera risible sin más. Es un crisol de géneros, de tradiciones, de ideas, motivos y figuras estilísticas heredados, de subterfugios tensados con el arte insuperable del narrador para comunicar, bajo la máscara de la risa, todo un programa de crítica contra los que están arriba.

\section{LA APOTEOSIS DE LAS MENTIRAS DE PESCADORES}

Un repertorio literario oral que parece muy caro a Landriscina, y en el que ha alcanzado cotas de calidad excepcional, es el de los cuentos de mentiras de pescadores. Reproduzco dos ejemplos muy notables, con la advertencia, una vez más, de que cada vez que Landriscina contaba una versión, producía un discurso con variantes, diferente de cualquier otro. Estos cuentos son: «Pescao / pescado de patio» y «El viejo mentiroso» los dos aparecen en antologías y se los repite con variantes. (Pendiente para el futuro queda la labor de comparación entre versiones, de la que podrían sacarse lecciones sin duda relevantes):

Pescado de patio.

Estoy haciendo memoria, a ver qué provincia nos falta. ¿Qué nos va a faltar? Provincia de Buenos Aires. Y yo les voy a contar un cuento digno de un paisano de Buenos Aires. Después les voy a contar otro, pero este va pal disco. El otro no se puede grabar porque es visual.

Paisano de la provincia de Buenos Aires yo to he visto en las fiestas en jinetadas, fiestas patrias. Con qué orgullo lleva su prenda y cómo la sabe usar. Porque claro, hay gauchos que visten de tanto en tanto, $\mathrm{y}$ hay otros que viven en gaucho porque tienen tareas rurales. Y usted los ve, che, por la manera de pararse sabe cuándo el hombre es de campo, tienen esa... Saca un cuarto de cola pa afuera como para estacionar. Y suele poner manos acá, a veces así.

\footnotetext{
${ }^{8}$ Sobre el tópico literario del puer senex hay una bibliografía internacional muy amplia. Téngase en cuenta una referencia actualizada: Luongo (2017).
} 
Y la conversación puede nacer de cualquier cosa. Por ahí uno dice:

— ¿Sabe que estoy aburrido?

Y le dice el otro, que ya encontró punta pa seguir con su relato:

- La vuelta pasada yo estaba también aburrido, che, taba aburrido. Un sábado a la tarde era; me acuerdo como si fuera hoy. Y dije: «¿qué hago?». Dije yo pa mí. Dije: «me voy a pescar», dije.

Y busqué la cosa y me jui. Busqué un recodo en el río que tuviera sombra, y me senté ahí; encarné y revolié la línea y la largué. Y estaba ahí; habrán pasado unos quince o dieciséis minutos y sentí un tirón, ni muy fuerte ni muy... tirón. Y yo dejé que venga el segundo y el tercero; y cuando vino el tercero, tiré para enganchar, y enganché y traje. Recojo, che, y sale un pescadito así.

Y me dio lástima de verlo tan chico, que dije: «lo voy a devolver al agua para que se haga hombre porque así no sirve para naa».

Y lo desenganché, este, lo desengancho con cuidado, para no lastimarle la boca, pobrecito. Le saco el anzuelo, y así nomas con la zurda lo largo para el agua.

¿Vos sabes que en el aire el pescado hace una pirueta y se vuelve para afuera por su propia voluntad? Y cae al lado mío, y me queda mirando como diciendo: «¿Qué me hace, mi amigo?». Como diciendo: «Si me sacó, me sacó, che». Como herido en su orgullo de pescado, como diciendo: «¿Qué digo ahora si vuelvo allá? ¿Que no sirvo para pescado?».

Y me dio como una vergüenza a mí, fijese; y me puse colorado; y lo agarré casi sin mirarlo, y lo puse en un balde con agua que yo suelo llevar para que no se le sequen las agallas de los pescados; y lo pongo allí.

Y ya estaba pescando, pero sin pescar, che, porque estaba intrigado con la actitud del pescado. Y el pescado se ve que pensaba en mí, porque me relojeaba desde el balde.

Y llegó el momento de dirse, porque ya había matado el tiempo como quería, porque yo estaba pescando por no por pescar, sino para matar el tiempo. Y pensé: «¿qué hago con este pescado?». Al río no quiere volver; matar, no lo voy a matar. Es un crimen con este pescado tan chico; y lo llevé para las casas.

Y lo entré a criar en la casa. A ratos en el fuentón, con la palangana; y lo iba cambiando según al tamaño. Y ya se me había criado; lo tenía en el bebedero. Porque lo crie con poca cosa; no era delicado; con galletas, así, esas cosas.

$Y$ usted sabe que en el campo tenemos una costumbre: cuando usted tiene un animal, le da de comer y le dice su nombre; y eso es como una campana para ellos; porque usted sabe que con la comida, ese sabe que es él. Y yo le puse Pancho.

Y le decía: «¡Pancho!». Al mes le decía «Pancho» desde la cocina, y él sacaba la cabeza, y yo le largaba la galleta, y él en el aire la abarajaba. Y ya era tremendo el pescado; y estaba en el bebedero porque no entraba en otro lado.

Y un día estaba yo tomando mate sentado en una silla petiza y siento un revuelo en el patio; salgo a ver: el pescado corriéndome los pollos.

Y fui y le dije: «No, Pancho, hermano; usted es pescado, hermano. Usted es pescado, hágame el favor». Y lo largué para el agua de un mal modo, porque me miró como diciendo «ufa» también; porque le mentiría si le diría que no tenía carácter, porque tenía su carácter el pescado.

Me vuelvo a la cocina para tomar; habré tomado tres mates. Me habré tomado tres mates más, cuando siento otra vez revuelo en el patio. Salgo otra vez: el pescado peleando con el perro, porque se tenían inquina los dos. Y allí le dije: «Vamos Pancho, ¿qué hacemos? Usted es del agua, hermano; no me ande por el patio».

Y vos sabes que lo metía en el agua y se me saltaba para el otro lado, como diciendo: «¡Acá estoy yo!». Y se me desacostumbró, che, de estar en el agua; y estaba afuera y se me hizo pescado de patio. Pero a tal forma, che, amigo, que a veces yo volvía del pueblo y sentía el galope de mi tobiano; y salía a la tranquera a esperarme, a hacerme fiesta; y es que el caballo quedaba desorientado, porque no tenía visto perro sin patas. 
Y el perro le tenía una envidia, porque pa colmo, cuando el pescado se aquerenció a estar afuera, cuando yo me sentaba, me trancaba a tomar mate; él así se arrimaba y jugueteaba con los flecos de la alpargata y se ponía cariñoso, y yo le pasaba la mano como si fuera un perro huachito 9 .

Y el Sultán le tenía una bronca al Pancho.

Un día, me acuerdo como si fuera hoy, un calor, y yo le dije al Pancho: «Che, Pancho, está calientito el día con sol. ¿Qué le parece si nos vamos al arroyo y nos pegamos una remojada?»

Y él me miró con una cara de agradecido que me conmovió, y nos fuimos los dos. El Sultán nos seguía de lejos a cincuenta metros atrás, con una bronca el perro.

Y llegamos a la orilla del arroyo en la parte honda, y me quedó mirando como diciéndome: «¿no se va a tirar con ropa?». Y me saqué la ropa y le dije al Pancho: «Bueno, ya estamos iguales mijo; a las tres, de zambullida».

Y dije: «una, dos y tres». Y nos largamos los dos juntos.

¿No me va a creer que se me ahogó, che? ${ }^{10}$.

\section{El viejo mentiroso.}

Se sabe que el único animal que crece después de muerto es el pescado, pues tiene un tamaño cuando lo sacan y otro cuando cuenta el que lo sacó, desde que el mundo es mundo.

Y justamente así como la gente de los talleres tienen un día, para comer. En el taller, aquí, los viernes es sagrado. Siempre buscan el viernes porque al otro día el sábado viene de aliviado, la cosa el sábado.

Este era un grupo que se juntaba, que cada uno tenía una tarea distinta, pero a todos les gustaba la pesca; entonces uno de ellos hacía de cocinero, y se iba rotando. Y después de comer se hacía una rueda y entraban a contar historias de pesca, de cacería y se bolacea$\mathrm{ba}^{11}$ a destajo.

Pero había uno del grupo, un viejo muy mayor, muy canoso, que por mayor no lo había revoleado de un chirlo, porque era muy mentiroso, pero ya exageradamente mentiroso; pero además no un mentiroso que vos decís «es simpático, ¿viste cómo inventa?». Además, si te reías él se enojaba, porque era cierto lo que él contaba.

Y uno de los circunstantes le dijo al dueño de la casa donde se hacía, al que tenía el quincho, el Mario.

- Mirá, Daniel, yo, a mí me encanta esta pausa de los viernes, porque uno se saca todas cosas del mate de la semana; me encanta comer variado con la habilidad de alguno de los que vienen, y me encanta lo otro, la charla. Pero no me lo banco más al viejo este, al Hilario Fabián; es insoportable, hermano, nunca podés ganar una, vos. Siempre te acuesta el viejo con algún bolazo; y bueno, porque es viejo uno lo tolera, pero yo ya estoy harto.

-Entonces, sabes vos que no es la primera protesta; vos no sos el único; pero no, no quiero que dejes de venir por eso; dejá que yo luego le voy a hablar al viejo, le voy a decir que afloje, porque hay dos o tres que están molestos también con el viejo.

Y se ve que lo habían hablado con el viejo; pero llegó el viernes, se cenó y, cuando entraron al bolaceo ${ }^{12}$, faaaa, el viejo se subió a un globo y no lo bajaban ni con flechas; y ya el Mario no se aguantó más y dijo:

\footnotetext{
${ }^{9}$ Huachito, 'huerfanito'.

${ }^{10}$ Transcribo el relato a partir de la versión en audio publicada con el título de «Pescado de Patio(Buenos Aires)

- Luis Landriscina» en «Luis Landriscina Oficial» (<https:/www.youtube.com/watch?v=gxmAlnhbCiw $>$ )

Esta versión lleva esta presentación: «Este viernes debe estar acompañado con uno de esos clásicos de Landriscina, Pescado de patio, un cuento sobre un gaucho de provincia de Buenos Aires».

${ }^{11}$ Bolazo en este contexto significa mentira.

${ }^{12}$ Bolaceo, relacionado con bolacero, 'Arg. Persona que acostumbra mentir y disparata', DRAE.
} 
-Discúlpenme señores, con ustedes no es la cosa, pero mientras siga viniendo este señor, al que respeto por las canas y por la edad que tiene, pero que se merecería que uno lo eche a patadas por mentiroso, y por irrespetuoso con los demás, mientras venga este señor, yo no vengo más. Discúlpenme el resto, porque con ustedes no es la cosa.

Y ya se iba yendo: - No, no Mario, vos no te tenés que ir; si alguien se tiene que ir es el viejo atorrante este.

Y ya lo basurearon al viejo. Porque todos estaban con ganas de decirle, pero no se animaban, porque era hombre que peinaba canas.

Y ya saltó.

- Tiene razón, a mí ya me tenía harto, acá está, pero que...

Y el viejo vio que perdía para siempre. Y el viejo, muy ladino, en vez de encocorarse, lo entró a trabajar por el lado de la lástima. Picarísimo el viejo.

-Está bien, no discutan más. Estaban demorando mucho, a mí me extrañaba que no lo habían dicho antes, porque es necesario que uno llegue a viejo para que entre a sobrar. Está bien. Los viejos sobramos en todos laos. Era justo que también sobre. Si me van a negar ese zoquete de carne que tiran en la parrilla para este pobre viejo, está bien, agárrenlo para uno más joven. A mí, no me... Total, uno está curtido de estas cosas. No voy a venir más.

Y todos lo miraron al otro como: «che, vos le dijiste...», porque todos lo que lo siguieron después lo dejaron solo. Y el Mario no se dejó atorar.

-Discúlpeme, don Hilario, usted está confundido. Acá nadie le está negando ese zoquete de carne que usted dice. Y si quiere venir a comer, venga, usted y los amigos de usted, porque acá no está tratando con ningunos egoístas; a comer, venga, lo que no queremos es que se quede a charlar después, porque usted no es un mentirosito de vez en cuando; usted tiene la mentira como sistema y es mal ejemplo para los más chicos, ¿entiende? Eso es lo que no queremos, que venga a seguir mintiendo, porque es un mal ejemplo, por mucha edad que usted tenga.

Y el viejo se quedó.

-Está bien, está bien, antes era un pedazo de carne; ahora es porque hablo; no hablo más. Ta bien, no voy a hablar. Yo les voy a contar antes de irme, por qué venía yo acá, yo venía porque soy hombre solo, no tengo perro que me ladre, y para sacarme los silencios de la semana esperaba, mire, como un chico espera un juguete, esperaba los viernes para juntarme con ustedes, para tener una posibilidad de charlar un ratito, de que me escuchen a tener con quiem hablar; pero si tampoco puedo hablar porque soy viejo, no voy a hablar más. Y me vía dir pal rancho y me voy a morir solo como un perro, que no se van a enterar, porque no va a haber nadie que les avise.

Y ya se mandó un sollozo.

Y todos lo miraban al Mario como diciendo: «perdona le la vida...». Nadie sabía cómo reaccionar. Y él le dice:

- Ta bien, si quiere venir, venga don, lo vamos a aceptar para que vea que no somos tan malos; pero eso sí, cuando vamos a entrar a hablar de pesca, usted no me agranda los tamaños, usted va a estar con las manos atadas; si no, no hay caso acá.

Y el viejo aceptó.

Y vinieron el viernes siguiente. Se comió y cuando se estaba en la ginebra y las grapas de sobremesa, entraron a hablar y le dijo:

-Espéreme, nosotros quedamos en algo; don Hilario: manos atadas.

Y el viejo se sorprendió, pero había aceptado las reglas de juego, y le puso las manos así y le ataron. Había traído hasta una soguita, el Mario. El Mario era el fiscal y le ató las cosas, y le ató la cosa y lo dejó con las manos atadas.

Y unos, sabes, que al viejo le ayudaron a prender el pucho, le servían el vino; pero nadie se las quería desatar, porque todos estaban encantados que el viejo tenga las manos atadas. 
Y cada uno mintió. Y dio la vuelta y le toca al viejo. Y por supuesto, el viejo no iba a contar si no podía mentir. Estaba ahí y le dice uno de los atrevidos, de esos que siempre se anima a ...

— ¿No va a contar nada, don Hilario?

-No sé... Lo que diga el hombre, por ahí. Por el Mario. Y el Mario le dice:

- Si se anima a contar, con la mano atada; si no, deje para otro día.

-Bueno, les voy a contar lo mismo.

Era un viejo muy ladino.

- La vez pasada, la noche de tormenta, no sé si se acuerdan que parece que se venía el mundo abajo; hará unos diez días, más o menos. Yo dije: «no voy a salir a pescar, porque soy de pescar a la noche, de encandilar». Pero la tormenta era muy brava; así que me fui al rancho a descansar un sueño, y me fui y me tiré. Y se ve que el perro del vecino se asustó con un trueno y me pechó ${ }^{13}$ la puerta del rancho mío y la dejó abierta. Y yo que estaba echado así. Miro, acostado como estaba, miro pal fondo así, y veo que estaba cortada la tormenta en el horizonte. Y yo dije para mis adentros: «está cortada la tormenta, no va a llover. Esto es pura bulla». Así que busqué la canoa, busqué el guijarro, y me fui, me fui al medio del río, crucé los remos y entré a encarnar. Encarné el primer anzuelo y tiré; encarné el segundo anzuelo y tiré. Cuando estaba encarnando el tercero... siento como que me pechan la canoa.

Y ahí se miraron todos como diciendo: «a este lo vamos a tener que acostar de un mazazo».

Y entonces dice uno:

— ¿Cómo era que le pechaban la canoa...?

- Sí, era como si me hubieran pechado; pero no era un pechazo. El primer anzuelo lo había mordido un bruto surubí y me estaba llevando de tiro. Entonces yo, que soy conocedor, le di soga, y le entré a ablandar la boca. Lo traía y lo largaba; y cuando como que cría que se había escapado de la línea, lo traía, y esos tirones lo vuelven loco al pescado y lo fui trayendo de a poco.

Y le dice uno:

- ¿Y... era grande?

- Tremendo.

- ¿Y lo pudo sacar?

- Si no lo via sacar...

- Pero si le tiraba la canoa debe haber sido grande...

- Grandísimo.

Y el Mario, che, como para acostarlo para siempre, para que no pueda hablar nunca más.

- ¿Y qué era lo que pescó?

-Un surubí, don Mario.

-Y, ¿lo sacó nomas?

Y para que quede bien en ridículo para siempre le preguntó:

- Y, ¿cómo era de grande el surubí?

Y el viejo, viste, dice que diablo sabe por diablo, pero más sabe por viejo, este tenía todas las picardías de viejo:

-Pero usted no me va a creer, don Mario: ¡cómo sería de grande ese pescado que los ojos eran más o menos así1 ${ }^{14}$ !

\footnotetext{
${ }^{13}$ Pegó con el pecho: pechar o empujar, tirar.

${ }^{14}$ Transcribo el relato a partir de una página de YouTube que lleva el título de «Viejo MentirosoLuis Landriscina» y se halla en la página «Luis Landriscina Oficial» (<https://www.youtube.com/ watch? $=$ Q $3 b Z e Z A W r I M>$ ) y añade esta especificación: «Hoy les compartimos Viejo Mentiroso grabado en el año 1994 en el Teatro Ópera de Buenos Aires, parte del disco 30 años de sonrisas».
} 
En el video del que he transcrito esta versión (una de las muchísimas que el narrador habrá contado y escenificado en su vida) se ve a Landriscina abriendo todo lo que puede las palmas de sus manos, aunque manteniendo juntas sus muñecas, como si en efecto las tuviese amarradas, mientras desde la nave del enorme teatro llega la ovación cerrada del público, que hasta unos segundos antes había estado absolutamente absorto, pendiente de sus palabras y gestos.

Muchas más reflexiones que las que nos permite el escaso espacio que tenemos podrían hacerse acerca de estos dos relatos. Me limitaré a señalar que, en el plano del estilo, de las inflexiones, del ritmo, del gesto, de la mirada, de los guiños cómplices al auditorio, Landriscina se nos presenta, otra vez, como un maestro absoluto: sus registros en video hacen mucha más justicia a su arte que cualquier reducción a texto y que cualquier lectura en silencio de sus relatos. Esta representando como los juglares contaban con gestos y movimientos, al mejor estilo popular.

Se pueden dar muchas interpretaciones, los relatos orales suelen invitar a reflexiones muy amplias, en el plano de las emociones, por ejemplo, vemos una pluralidad de tonos. Los dos relatos son cómicos en el sentido de que rompen con lo esperado, pero al mismo tiempo invitan a una profunda reflexión sobre la piedad, la solidad, el perdón y acerca de la posibilidad que a veces se concede a los débiles y a los vencidos, de levantarse, de salir adelante en las condiciones más adversas, en situaciones de reclusión, de exclusión, de marginación. De hecho, en uno de los cuentos el pescador se duele, tiene compasión del animalito que ha pescado, lo libera del anzuelo y acaba trabando una amistad profunda y ligando su destino al destino de él; en el otro relato, el viejo expulsado porque sus cuentos de mentiras de pescadores enervan a otras personas es perdonado a duras penas... oportunidad que él aprovecha para volver a contar sus apoteósicas patrañas y para volver a reivindicarse como excelente administrador del logos, como habilísimo y triunfador héroe-trickster traductor. Los débiles se levantan con sus conductas inusuales y la gracia la causa esa ruptura de lo esperado.

Las posibilidades de comparación son muchísimas. En el monumental MotifIndex de motivos folclóricos del mundo, de Stith Thompson (1955-1958), encontramos entradas como X1100-X1199 (Lie: great hunters and fishermen), X1150 (Lies about fishing), X1300 (Lies about fish), X1301 (Lies: the Great Fish), X1306 (Lie: Tamed Fish Lives on Dry Land). Ello prueba no solo que las mentiras de pescadores a las que tan aficionado es Landriscina son un repertorio consagrado en las artes verbales de no pocas culturas del mundo, sino también que algunos de los motivos narrativos más concretos y característicos de estos relatos argentinos forman parte de la amplísima y pluricultural corriente de la literatura oral internacional.

Las tradiciones acaso reminiscentes se acumulan. En lo que se refiere al relato Pescado de patio, el pez que se acomoda a vivir en la tierra firme y el amigo humano del pez, que se va con él para intentar la aventura del agua, podrían estar en la órbita (aunque en posiciones muy distantes) de leyendas del tipo de la del fantástico pez Nicolás (que tiene vínculos probables, dicho sea de paso, con el género de las mentiras de pescadores), que en sus primeros años había sido, se contaba, un niño que prefirió el agua como espacio vital ${ }^{15}$. Hay otros relatos fascinantes acerca de peces que salen de las aguas para vivir provisionalmente entre los humanos, como se ha contado muchas veces acerca de

${ }^{15}$ Sobre el personaje existe una bibliografía muy profusa. Véanse especialmente Agostino (2008) y Delpech (2015). 
los delfines rosas (o botos) de algunas cuencas fluviales del Sur de América. Se pueden consultar Slater (1994), Pedrosa (2001) y el documental de Galeano «Los árboles también tiene madre» (2008).

Las influencias de las tradiciones orales nativas de América también son fundamentales. En muchos relatos y leyendas se cuenta que el hombre pierde su condición humana como castigo divino o lo elige por medio de la magia, tomar la condición animal por un tiempo limitado. Así mismo el animal puede tomar características humanas en relatos míticos y fantásticos y este cruzamiento de ida y vuelta dibuja una frontera permeable entre lo animal y lo humano. El humor y el drama también se entrelazan en estos relatos.

En lo que respecta al cuento de El viejo mentiroso, protagonizado por un inventor impenitente de mentiras que enfadan a las personas del entorno, recuerda por supuesto a la novela Os velhos marinheiros (1961) del brasileño Jorge Amado, que nos presenta a dos viejos marinos a los que enemista su competencia en la invención de cuentos de mentiras; o a la novela Big Fish: A Novel of Mythic Proportions (1998) del norteamericano Daniel Wallace (de ella surgió la célebre película Big Fish, 2003, de Tim Burton), acerca de un viejo cuya manía de contar mentiras de pescadores le procura hasta la enemistad de su familia. Las no pocas (y a veces iracundas) reconvenciones de don Quijote a Sancho, por su locuacidad muchas veces desbordante y enervante, podrían hallarse también en la órbita de este motivo. En el horizonte lejano del enfrentamiento del ser humano y del ser animal del cuento de Landriscina puede que esté también la tradición de la que salieron los relatos inmortales Moby Dick (1851) de Hermann Melville y The Old Man and the Sea (1952) de Ernest Hemingway, con sus épicas luchas contra la bestia acuática.

Más allá de las comparaciones y paralelos con la literatura clásica, es interesante leer un reportaje periodístico que fue publicado el día 24 de octubre de 2019, en un diario digital argentino:AGNoticias que se publica en la ciudad de Alta Gracia, de la provincia argentina de Córdoba. Donde detalla como Landriscina escucha a su joven admirador que le pide que cambie el final del cuento «Pescado de patio» porque le parecía muy triste. Así se resume la historia real. ${ }^{16}$

\section{Luis Landriscina tomó contacto con el niño que estaba buscando}

La historia de Luis Landriscina y un pequeño admirador nació en nuestra ciudad, en pleno festejo por los 50 Años de la Misión Argentina. Ayer, tuvo su final feliz.

La fiesta por los 50 años de la hazaña de los pilotos argentinos en las 84 horas de Nürburgring en la Fortaleza de Oreste Berta en Alta Gracia dejó una conexión especial entre Luis Landriscina, uno de los destacados invitados, y un pequeño fanático de 11 años. Allí, el humorista le hizo una promesa: cambiaría el final de uno de sus cuentos para él.

Pocos días después de aquella gran fiesta, en AGNoticias dábamos cuenta de la intención de Don Luis de encontrar y tomar contacto con este niño.

El comediante relató este miércoles a Cadena 3 que se conmovió con el abrazo que le dio el niño, Juan Ignacio Cabrera, quien se acercó al escenario y le pidió sacarse una foto.

«Me abrazó como a un abuelo que hace mucho no veía. Yo lo abracé como a un nieto. La abuela ahí me dijo 'este chico no es cualquiera. Quiere una foto porque lo eligió a usted en YouTube. Quiere escuchar sus cuentos. Estoy muy feliz, porque hay tanta porquería en internet y lo eligió», relató.

${ }^{16}$ (Ver: https://www.altagracianoticias.com/encuentro-torino-luis-landriscina-busca-al-nino-que-losaludo-en-el-escenario/) 
Lo que más sorprendió al artista es que el chico, para escuchar los cuentos, apaga la luz para imaginarse en la oscuridad lo que él cuenta con sus palabras. «Me temblaron las piernas y nos abrazamos de nuevo. La abuela se largó a llorar. Quiero hablar con él y que me cuente lo que siente y cómo dibuja en su imaginación. Es un rasgo de inteligencia. «Me provocó una cosa muy especial, era de una gran ternura», destacó.

Landriscina lamentó no haber podido contactarse con el chico después de la corta reunión, por lo que emprendió una campaña para conseguir al menos su teléfono. Esa búsqueda concluyó este miércoles por la tarde tras su entrevista con Cadena 3, ya que su abuela, Amanda, llamó a la radio y dialogó con Rony Vargas.

«Estoy muy emocionada. Yo también lo busqué a Luis, pero no tenía cómo escribirle y decirle. Estamos esperándolo, porque nos prometió que le va a cambiar el final al 'cuento del pescado de patio'. Es divino mi nieto. Vienen con su hermano a dormir a mi casa y para que no miren tanta tele empecé con este juego para que escuchen cuentos de Luis apagando la luz», describió la mujer, que vive en barrio Villa Cabrera de la capital cordobesa.

Y explicó el porqué de la promesa: «Luis me prometió que iba a cambiar el final porque era triste, ahí el pescado se moría. Nos dijo que lo iba a modificar».

(Fuente: Cadena 3)

En esta pequeña nota periodística vemos cómo Landriscina como creador y narrador popular se permite variaciones de las historias para favorecer el pedido del público. En este caso es un chico que elige un final más feliz para su historia preferida. Es así como vemos el repertorio pleno de variantes, el narrador que es capaz de establecer nuevas versiones y el compromiso entre artista y público que consiguen sellar con un abrazo apretado aquí, en una comunicación que empezó en YouTube y sigue en la vida real. Un escritor como Borges o Cortazar no hubieran permitido que se cambiara una coma de sus textos escritos y esto es propio de la literatura. Landriscina, creador popular oral y difusor de folklore, dueño de un repertorio rico en profundidad y cantidades, difusor y creador o mejor dicho co-creador de historias sin fin, puede cambiar y modificar por la reacción de los que frente a él participan de su proceso creador. Es por esto mismo que esperamos una larga vida a la tradición oral, así en los fogones como en el mundo digital. Y vale la pena ver las relaciones entre los textos orales y escritos, clásicos o apenas conocidos. Lo que es importante afirmar es que la participación digital que es una nueva tribuna o la profesionalización del contador, no los elimina del universo tradicional y estudiar a estos creadores y su repertorio nos permite trazar innumerables mapas de entrecruzamiento entre lo oral y lo escrito, lo tradicional y lo masivo.

\section{OBRAs CITADAS}

Agostino, Maria D' (2008): La leggenda di Cola Pesce. Una versione spagnola del secolo XVII, Roma, Salerno Editrice.

Bennett, Gillian, y Smith, Paul (2007): Urban Legends: A Collection of International Tall Tales and Terrors, Westport, CT: Greenwood Press, 2007.

CAron, James E. (1986): «The Violence and Language of Swapping Lies: Towards a Definition of American Tall Tale», Studies in American Humor, New Series 2, pp. 27-37.

Chevalier, Maxime (1999): «Cuentos de mentiras», en Cuento tradicional, cultura, literatura (siglos XVI-XIX), Salamanca, Universidad, pp. 67-74. 
DÉGH, Linda (1994): American Folklore and the Mass Media, Indiana, Indiana University Press.

DelPeCh, François (2015): «La métamorphose marine de Cola Pesce: mythe, folklore, littérature», Bulletin hispanique, 117, pp. 615-644. DOI: https://doi.org/10.4000/ bulletinhispanique.4091

DíAZ VianA, Luis (2003): «La aldea fantasma: problemas en el estudio del folklore y la cultura popular contemporáneos», Revista de dialectología y tradiciones populares, 58, pp. 29-46. DOI: https://doi.org/10.3989/rdtp.2003.v58.i1.162

DíAz Viana, Luis (2004): El nuevo orden del caos: consecuencias socioculturales de la globalización, Madrid, CSIC.

Fee, Christopher R. y Webb, Jeffrey B. (eds.) (2016): American Myths, Legends, and Tall Tales: An Encyclopedia of American Folklore, 3 vols., s. 1., ABC-CLIO.

Galeano, Juan Carlos (2008): Trees Have a Mother: Amazonian Cosmologies, Folktales and Mystery, Films Media Group, 2008.

García De EnTERríA, María Cruz (1983): Literaturas marginadas: Lectura crítica de la literatura española, Madrid, Editorial Playor.

Henningsen, Gustav [traducción al inglés de Warren E. Roberts] (1965), «The Art of Perpendicular Lying. Concerning a Commercial Collection of Norwegian Sailors' Tall Tales», Journal of the Folklore Institute, 2, pp. 180-219. DOI: https://doi. org $/ 10.2307 / 3813833$

LANDRISCINA, Luis (1995): «Alcances terapéuticos del humor», Enfoques 7, pp. 55-62.

LANDRISCINA, Luis (1999): Lo mejor de Luis Landriscina, Buenos Aires, Imaginador Libros.

Lara Garrido, José (1982): «Los Diálogos de la montería: desestructuración expositiva y coherencia compendial», Boletín de la Biblioteca de Menéndez Pelayo, 58, pp. 115-153.

LuONGO, Salvatore (2017): «Señor, dizen de la estoria del viejo: el cuento Senex caecus del Sendebar», Memorabilia, 19, pp. 79-89.

Martínez Reyes, Fernanda María (2016): La narrativa oral en Honduras: nuevas exploraciones en los inicios del siglo XXI, tesis doctoral, Alcalá de Henares, Universidad.

Meyer-Minnemann, Klaus y Schlickers, Sabine (eds.) (2008): La novela picaresca. Concepto genérico y evolución del género (siglos xvi y xvii), Madrid / Frankfurt am Main, Iberoamericana / Vervuert (Biblioteca Áurea Hispánica, 54), 2008. DOI: https://doi.org/10.31819/9783865279644

Pedrosa, José Manuel (2001): «Si los delfines mueren de amores...: de la antigüedad clásica a los botos seductores del Amazonas», Anuario de Letras 39, pp. 351-368.

Pedrosa, José Manuel (2008): «Sayagueses, charros, batuecos y sandios: los mitos del rústico tonto en los Siglos de Oro», L'imaginaire du territoire en Espagne et au Portugal (XVIe-XVIIe siècles), ed. François Delpech, Madrid, Casa de Velázquez, pp. 309-326.

Pedrosa, José Manuel (2018): «Straparola, Truchado y el debate del campesino y el clérigo (ATU 1562A): una vindicación del héroe traductor y de la cultura popular», eHumanista, 38 [«Compuestas fábulas, artificiosas mentiras», La novela corta del Siglo de Oro, número monográfico coordinado por David González Ramírez y M. Ángeles González Luque], pp. 364-410.

Pedrosa, José Manuel (2019): «Novela picaresca, cuento de mentiras y cuento de trickster: homodiégesis y autoficción, entre escritura y oralidad», Perspectivas 
sobre poéticas orales. $2{ }^{\circ}$ Congreso Internacional «Poéticas de la oralidad», eds. Berenice Granados y Santiago Cortés, Morelia, México, 1-59.

Pedrosa, José Manuel (2021): «Straparola, Truchado y el cuento de El criado veraz (ATU 889): oralidad, escritura, traducción y parresia», Cuadernos de filología italiana, 28 (2021), en prensa.

Pieretti, Ricardo (2012): Os contadores de causos e a poética dos Pantanais, Campo Grande: Life Editora.

Romero Tobar, Leonardo (1999): «Entre 1898 y 1998: la historiografía de la literatura española», Rilce, 15, 27-49.

SANFILIPPO, Marina (2007): El renacimiento de la narración oral en Italia y España (19852005), Madrid: Fundación Universitaria Española.

Schmitz, Neil (1977): «Tall Tale, Tall Talk: Pursuing the Lie in Jacksonian Literature», American Literature, 48, pp. 471-491. DOI: https://doi.org/10.2307/2925215

Slater, Candace (1994): Dance of the Dolphin. Transformation and Disenchantment in the Amazonian Imagination, Chicago, University Press. DOI: https://doi. org/10.7208/chicago/9780226924892.001.0001

Thompson, Stith (1955-1958): Motif-Index of Folk Literature: a Classification of Narrative Elements in Folktales, Ballads, Myths, Fables, Mediaeval Romances, Exempla, Fabliaux, Jest-Books and Local Legends, ed. rev. y aum., 6 vols., Bloomington \& Indianapolis-Copenhague, Indiana University-Rosenkilde \& Bagger.

Villalón, Cristóbal de (1967): El Scholástico, ed. Richard J. A. Kerr, Madrid, CSIC.

Wonham, Henry B. (1989): «In the Name of Wonder: The Emergence of Tall Narrative in American Writing», American Quarterly, 41, pp. 284-307. DOI: https://doi. org/10.2307/2713026

Fecha de recepción: 28 de marzo de 2021

Fecha de aceptación: 13 de mayo de 2021

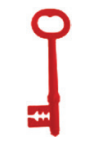

